\title{
Sistem Monitoring Kinerja Dosen Pada Institusi Perguruan Tinggi Swasta (Studi Kasus: Universitas Abdurrab)
}

\author{
Salamun $^{1}$, Diki Arisandi ${ }^{2 *}$ \\ ${ }^{1,2}$ Program Studi Teknik Informatika, Fakultas Teknik, Universitas Abdurrab \\ 1,2Jl. Riau Ujung No.73, Pekanbaru, Riau, telp. 0761-38762 \\ e-mail: ${ }^{1}$ salamun@univrab.ac.id, ${ }^{2 *}$ diki@univrab.ac.id
}

\begin{abstract}
Abstrak
Dosen dalam aktivitas keseharian memiliki tiga kewajiban yang dikenal dengan "Tridharma perguruan tinggi". Kurangnya monitoring kinerja dosen dalam beberapa kegiatan yang wajib menyebabkan pimpinan universitas sulit mendapatkan laporan yang rutin dari dosen, sistem ini dibangun berbasis web dengan metode waterfall. Fungsi yang terdapat dalam sistem mencakup input kinerja dosen dalam bidang tri darma perguruan tinggi, yang akan menghasilkan laporan kinerja beserta jam kerja dosen setiap minggu nya. Beberapa pihak seperti atasan Dosen, Asesor, dan pihak kepegawaian di Universitas perlu melakukan monitoring terhadap perkembangan aktivitas setiap dosennya pada tiap semester. Penelitian ini dimulai dari penelusuran referensi pedoman angka kredit dari kementerian pendidikan dan kebudayaan, setelah itu kami melakukan wawancara dengan pihak dari kepegawaian untuk perancangan sistem monitoring yang akan dibuat. sistem yang dibuat menggunakan kerangka kerja waterfall dan pemodelan sistem menggunakan unified modelling language (UML). Sebelum sistem diimplementasikan, pengujian diawali dengan membagikan panduan pengguanaan terlebih dahulu dan memberikan kesempatan kepada entitas yang terlibat untuk mempelajarinya. Pengujian lebih ditekankan pada aspek penguasaan terhadap penggunaan sistem ini. Hasil dari penelitian ini yaitu sistem yang dapat merekam kinerja seluruh dosen secara digital, dan informasi kinerja dosen dapat diakses oleh pihak universitas untuk dijadikan bahan untuk penilaian kinerja dimasa mendatang.
\end{abstract}

Kata kunci: kinerja, monitoring, sistem, Tridharma perguruan tinggi, dosen.

\section{Abstract}

Lecturers in their daily activities have three obligations, known as "three pillars of higher education." Insufficient monitoring of lecturers' performance in their mandatory activities may cause difficulty for university leaders to obtain regular reports from lecturers. We built a system on a web-based basis with the waterfall method, contained an input page for the performance of lecturers in their mandatory activity, which will generate performance reports, including the working hours every week. Some Persons are required to monitor the activities of each lecturer in every semester. We started to trace the reference for the credit score guideline from the ministry of education and culture, then we conduct interviews with Human Resources Department for monitoring system design. The systems created using the waterfall framework and system modeling using the unified modeling language (UML). Before implementation, we were conducting testing by sharing the user guide and giving the involved entities the opportunity to learn it. Testing is more emphasized on aspects of mastery of the use of the system. The outcome of this work is a system that can record the performance of all lecturers digitally, and lecturer performance information can be accessed by the university as a materiall for further assessments.

Keywords: performance, monitoring, system, three pillars of higher education, lecturer.

\section{Pendahuluan}

Pada sebuah institusi perguruan tinggi, keberadaan dosen mutlak dibutuhkan untuk menjalankan kegiatan tridharma perguruan tinggi dan sudah menjadi kewajiban dosen itu sendiri [1]. Disamping tridharma yang menjadi kewajiban, sebagian dosen juga memiliki 
amanah tambahan yaitu menduduki jabatan tertentu pada institusi yang bersangkutan maupun berkegiatan diluar institusi mereka. Hal ini perlu dilakukan agar dosen memiliki relasi dan pergaulan yang luas untuk pengembangan diri [2].

Pendidikan merupakan unsur pertama dari Tridharma Perguruan Tinggi. Pendidikan mempunyai peranan penting pada proses pembelajaran. Telah dinyatakan dalam Undang undang pendidikan tinggi yaitu pendidikan adalah usaha sadar dan terencana untuk mewujudkan suasana belajar dan proses pembelajaran agar peserta didik secara aktif mengembangkan potensi dirinya [3]. Kewajiban kedua yaitu penelitian, tujuan utamanya adalah untuk pengembangan ilmu yang ada dan mencari hal-hal baru. Sehingga dari penelitian, maka diharapkan Dosen mampu mengembangkan ilmu dan teknologi sehingga mampu menjalankan perannya sebagai agent of change ditengah-tengah masyarakat [4]. TriDharma yang ketiga adalah pengabdian pada masyarakat. Bentuk pengabdian yang dilakukan dosen kepada masyarakat, misalnya melalui pemberdayaan organisasi-organisasi kemasyarakatan, penyuluhan, pendampingan kegiatan masyarakat, transfer ilmu / teknologi tepat guna, dan lain sebagainya [5]. Disamping aspek Tridharma, ada beberapa Dosen diberikan amanah tambahan berupa jabatan dilingkungan perguruan tingggi [6] atas berbagai pertimbangan seperti prestasi, lama kerja, jabatan akademik, dan lain sebagainya.

Bagi Dosen di institusi perguruan tinggi swasta, tiga kewajiban yang terdapat dalam tridharma wajib dilaporkan kepada pihak institusi maupun ke Lembaga Layanan Pendidikan Tinggi (LLDikti) bagi yang sudah bersertifikasi pada setiap semesternya [7]. Pelaporan kinerja dosen secara rutin mutlak dibutuhkan oleh setiap institusi perguruan tinggi untuk memonitoring apa saja yang telah dilakukan dosen pada setiap periodenya [8]. Hasil dari pelaporan kinerja akan menjadi pertimbangan dari pihak institusi untuk memberikan bonus, tunjangan, promosi, demosi, dan bahkan penghentian kontrak kerja bagi yang tidak dapat mencapai target kinerja [9]. Dalam hal jumlah dosen khususnya Universitas Abdurrab, institusi ini memiliki dosen yang bersertifikasi berkisar $48 \%$. Tentunya hal ini juga mempengaruhi angka partisipasi dosen di Universitas abdurrab dalam melaporkan kinerjanya.

Ada beberapa persoalan yang peneliti lihat terkait kegiatan monitoring aktifitas dosen, khususnya bagi Perguruan tinggi swasta dan Universitas Abdurrab. Bagi dosen yang belum memiliki sertifikasi sebagai dosen profesional, kesadaran untuk mengumpulkan dan melaporkan bukti kinerja masih belum seperti dosen yang telah tersertifikasi. Hal ini berakibat kepada bukti kinerja dosen yang bersangkutan tidak terekam sepenuhnya, dan tentunya akan merugikan pihak perguruan tinggi. Persoalan yang lain yaitu terletak pada sistem yang berjalan untuk dosen yang telah tersertifikasi. LLDIKTI wilayah X yang menaungi Universitas Abdurrab memang sudah menggunakan sistem berbasis online untuk pelaporan yang bisa diakses pada halaman http://simdos.lldikti10.id, namun hanya untuk keperluan pelaporan ke LLDIKTI wilayah X saja. Bagi dosen tersertifikasi yang akan membuat perencanaan dan pelaporan hanya dibekali aplikasi portabel secara offline, yang mengakibatkan kurangnya kontrol dari atasan, asesor, maupun pihak perguruan tinggi pada saat proses berjalannya kegiatan yang direncanakan.

Peneliti menganggap perlu ada sistem informasi yang dapat memonitoring kinerja dosen tanpa memandang apakah dosen tersebut telah bersertifikasi atau belum. Selain itu, sistem yang dirancang harus dapat diakses oleh Dosen, atasan Dosen, Asesor, maupun pihak perguruan tinggi secara online, sekaligus dapat memonitor sejauh mana aktivitas yang telah direncanakan diawal semester. Sehingga dengan adanya sistem ini, progres setiap aktivitas dosen dapat dipantau tanpa harus menunggu pelaporan diakhir semester. Berdasarkan penjelasan yang telah diuraikan sebelumnya, peneliti perlu membuat sebuah sistem informasi yang dapat memonitor aktifitas dosen. Sehingga aktifitas dosen dapat terus dipantau oleh atasan maupun asesor secara online tanpa harus menunggu hingga akhir semester.

Sistem informasi merupakan integrasi antara manusia dan mesin dalam mengubah data menjadi informasi [10]. Sistem informasi menyediakan informasi yang berguna untuk manajemen dalam pengambilan keputusan dan juga untuk menjalankan operasional perusahaan secar rutin [11]. Sistem informasi merupakan gabungan dari manusia, teknologi informasi, dan berbagai prosedur yang tergorganisasi [12]. Namun, dalam mentransformasikan sebuah 
informasi yang berasal dari data, diperlukan relevansi, ketepatan waktu, dan keakuratan dari informasi itu sendiri [13]. Penerapan sistem informasi telah banyak diaplikasikan seperti pada bidang kesehatan [14], bidang penjualan atau pembelian barang dan jasa [15], bidang akademik [16], bidang kepegawaian pada sekolah [17], dan juga seperti yang dilakukan oleh peneliti pada penelitian ini yaitu membangun sistem monitoring kinerja dosen di perguruan tinggi swasta.

\section{Metode Penelitian}

Pada penelitian ini, diperlukan beberapa data diantaranya data primer dan data sekunder. Pengambilan data secara primer dilakukan dengan mewawancarai pihak yang terkait dengan sistem monitoring atau LKD/BKD (Laporan Kinerja Dosen / Beban Kerja Dosen) yang selama ini digunakan oleh dosen, dalam hal ini adalah dosen bersangkutan yang telah tersertifikasi dan bagian kepegawaian. Data sekunder dalam penelitian ini adalah panduan atau rubrik BKD yang dikeluarkan oleh Kementerian Ristek dan Dikti tahun 2019, dimana peneliti memerlukan data bobot atau kredit poin yang diberikan untuk setiap aktifitas yang dilaporkan oleh dosen yang bersangkutan.

Penggunaan metode dalam melakukan rancangan sistem pada penelitian ini seperti yang terlihat pada gambar 1 memakai sekuensial linear / Waterfall. Model ini yaitu model yang digunakan untuk pengembangan software yang lazim dan paling banyak dipakai, dikarenakan kejelasan struktur pengerjaan, waktu pengerjaan / time schedule, dan material yang dipakai saat pengerjaan pengembangan perangkat lunak [18]. Model ini menggunakan pendekatan dalam hal mengembangkan perangkat lunak secara sekuensial dan juga sistematis, yang dimulai dengan perencanaan kebutuhan, analisis sistem, perancangan sistem, implementasi, dan pemeliharaan sistem [19],[20].

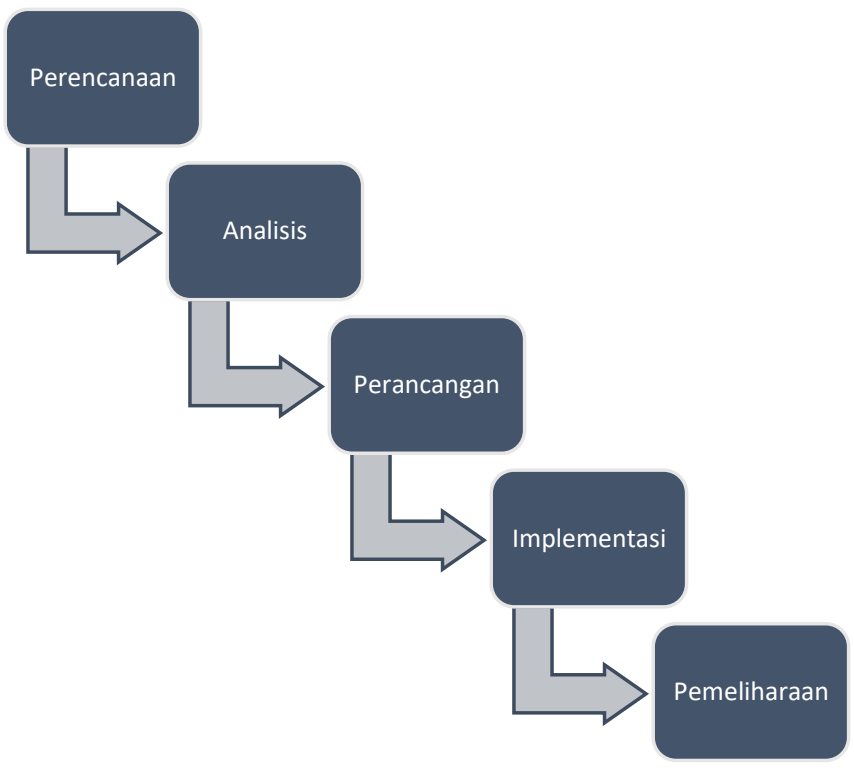

Gambar 1. Tahapan Pada Model Waterfall

Pada tahapan perancangan sistem, peneliti memakai tool perancangan yang berupa diagram UML (Unified Modelling Language). UML yaitu bahasa yang digunakan dalam memvisualisasikan dan mendokumentasikan artifacts, yang merupakan bagian dari informasi yang digunakan untuk proses perancangan sistem atau perangkat lunak. Artifact yang dimaksud bisa berupa deskripsi, model, atau perangkat lunak seperti pada pemodelan bisnis dan sistem non perangkat lunak lainnya [21]. Diagram UML memungkinkan tidak hanya developer maupun analyst untuk memahami visualisasi sistem, namun juga berlaku untuk pihak awam. Selain itu, konsep OO (Object-Oriented) digunakan untuk bahasa pemodelan pada UML ini [22],[23]. 


\section{Hasil dan Pembahasan}

Berdasarkan kondisi sistem yang berjalan selama ini pelaporan kinerja dosen masih dalam bentuk laporan cetak yang dibuktikan dengan adanya dokumentasi kegiatan yang setiap minggunay wajib dilaporkan dosen kepada pimpinan fakultas, setelah pimpinan fakultas memeriksa maka laporan akan diserahkan pada pimpinan universitas. Dengan system yang seperti ini beum bisa dilihat secara rinci apa saja yang dikerjakan dosen dan bagaimana pembagian sks serta jam kerja pada setiap minggu. Maka peneliti membuat usulan aliran sistem monitoring seperti pada gambar 2 berikut dengan menambahkan rancangan sistem berbasis web agar dapat diakses dengan mudah, namun tetap mengadopsi dari alur sistem yang berjalan.

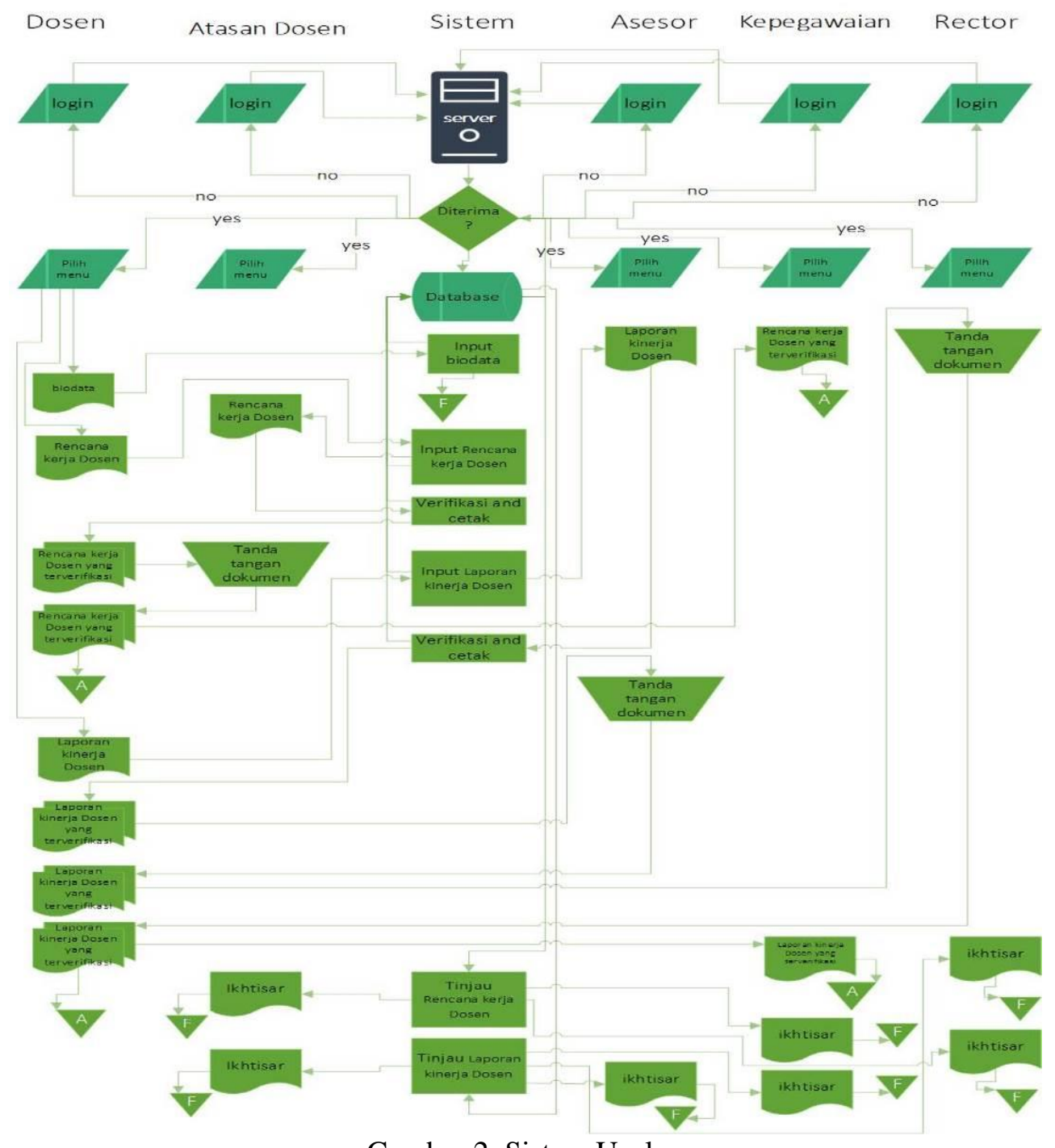

Gambar 2. Sistem Usulan

Perubahan sistem usulan terletak pada seluruh aktivitas yang dilakukan oleh entitas yang terlibat dilakukan pada server. Entitas yang terlibat memiliki hak akses masing-masing sesuai dengan perannya seperti yang digambarkan pada gambar 3. Kegiatan penginputan rencana kerja Dosen dapat dilihat, dimonitoring, dan diverifikasi oleh atasan Dosen. Begitu juga laporan kinerja Dosen yang dilihat, dimonitoring, dan diverifikasi oleh Asesor. Seluruh rencana kerja dan laporan kinerja dapat dilihat oleh pihak personalia dan Rektor, yang nantinya dapat menjadi bahan pertimbangan untuk Dosen yang bersangkutan.

Sebagai gambaran pihak yang terlibat dalam sistem yang dibangun dan apa saja aktifitas yang dapat dilakukan oleh entitas yang terlibat, maka peneliti membuat visualisasi dalam bentuk Use Case yang merupakan salah satu dari diagram UML pada gambar 3 berikut. 


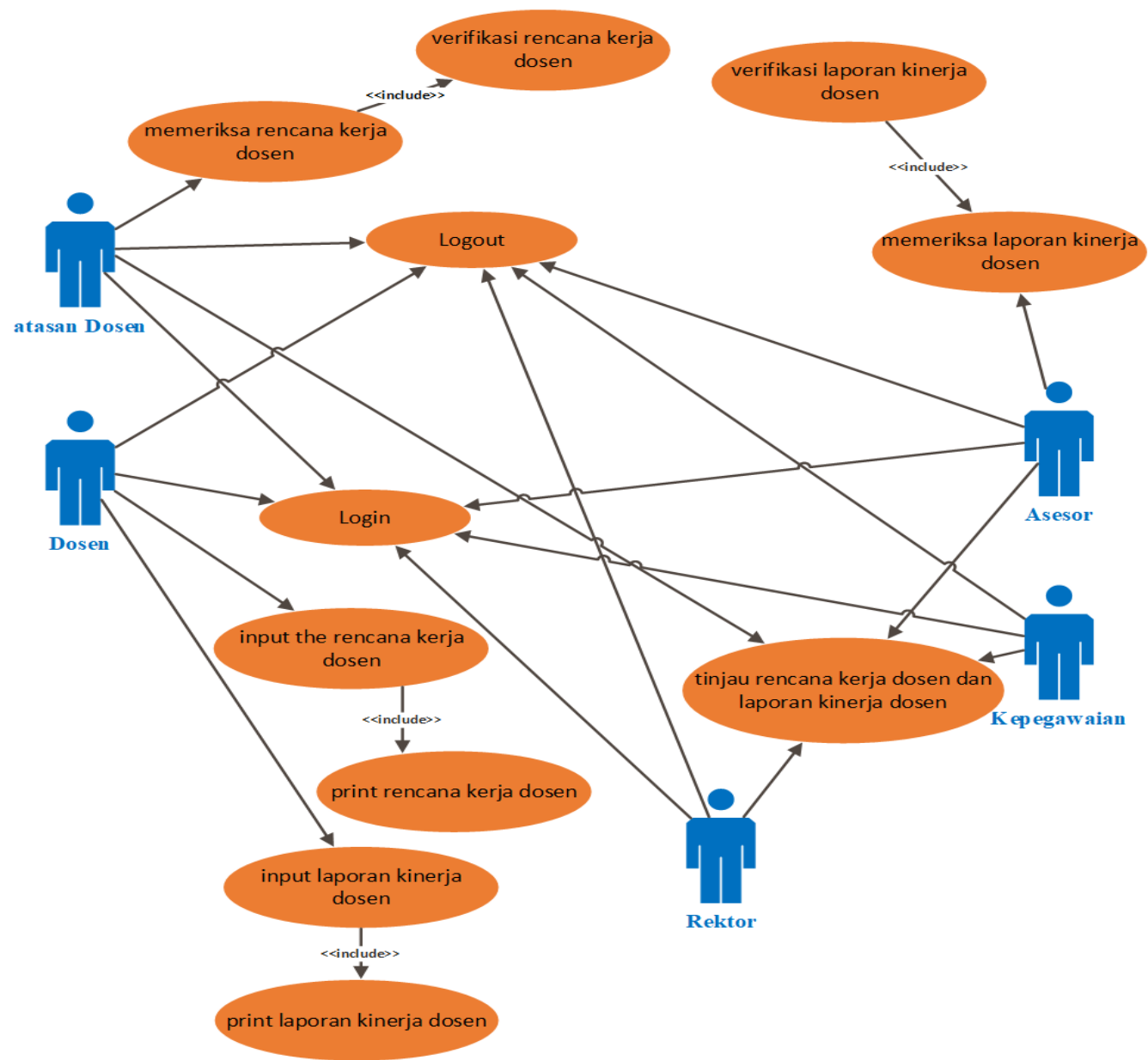

Gambar 3. Diagram Use Case

Pada diagram Use Case dapat terlihat bahwa kegiatan penginputan rencana kerja dan laporan kinerja tidak berbeda dari sistem sebelumnya, yaitu tetap diawasi dan diverifikasi atasan dosen maupun asesor. Namun penambahan yang ada pada sistem ini, selain dibuat secara online, pihak kepegawaian dan Rektor dapat juga memonitor aktivitas yang dilakukan oleh Dosen yang bersangkutan. Sistem monitoring yang dibangun dapat diakses pada halaman http://bkd.univrab.ac.id. Pada gambar 4, Setiap entitas yang terlibat terlebih dahulu harus login untuk dapat mengakses sistem monitoring ini.

Penelitian ini menghasilkan sebuah system yang harus mengacu pada kebijakankebijakan universitas, diantaranya: setiap dosen wajib melaporkan kinerja tri darma perguruan tinggi setiap minggunya melalui aplikasi, setiap dosen diwajibkan memenuhi jam kerja besar sama dengan 7 jam setiap harinya, setiap dosen wajib mengisi kinerja pendididkan, penelitian, serta pengabdian, dan setiap dosen diwajibkan melampirkan bukti kinerja saat pengisian aplikasi, karena setiap alur penggunaan aplikasi ini dosen akan di tuntut untuk mengisi poinpoin pertanyaan yang berhubungan dengan kinerja mereka, dalam penelitian ini mengambil item pertanyaan yang mengacu pada rubrik tahun 2019. Setiap pertanyaan memiliki bobot SKS tertentu seperti bidang Pendidikan, dosen di tuntut minimal memilikik inerja minimal 9 SKS, sedangkan pada bidang penelitian, pengabdian, dan penunjang dosen di tuntut memiliki kinerja minimal 2 SKS setiap bidangnya.

Dalam penelitian ini rumus yang digunakan untuk perhitungan total SKS dosen menggunakan rumus yang terdapat pada rubrik tahun 2019. Tujuan dalam pembuatan perhitungan ini adalah untuk melihat total SKS kinerja dosen. Pelaporan dapat dilihat mingguan maupun bulanan. Penelitian ini juga harus mengacu pada kebijakan-kebijakan yang dibuat oleh 
rector universitas seperti metodei inputan di teteapkan satu kali dalam satu minggu, semua kinerja wajib di inputkan dalam satu hari tidak boleh di cicil.

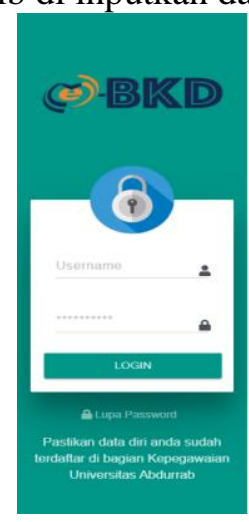

\section{BKD UNIVRAB \\ (i) $\odot \odot$}

\section{Gambar 4. Halaman Login}

Setelah login, pada gambar 5 entitas yang memiliki akses akan masuk ke tampilan dashboard masing-masing. Pada dashboard, dapat dilihat biodata dan dokumen pendukung lainnya yang dapat diunggah kedalam sistem.

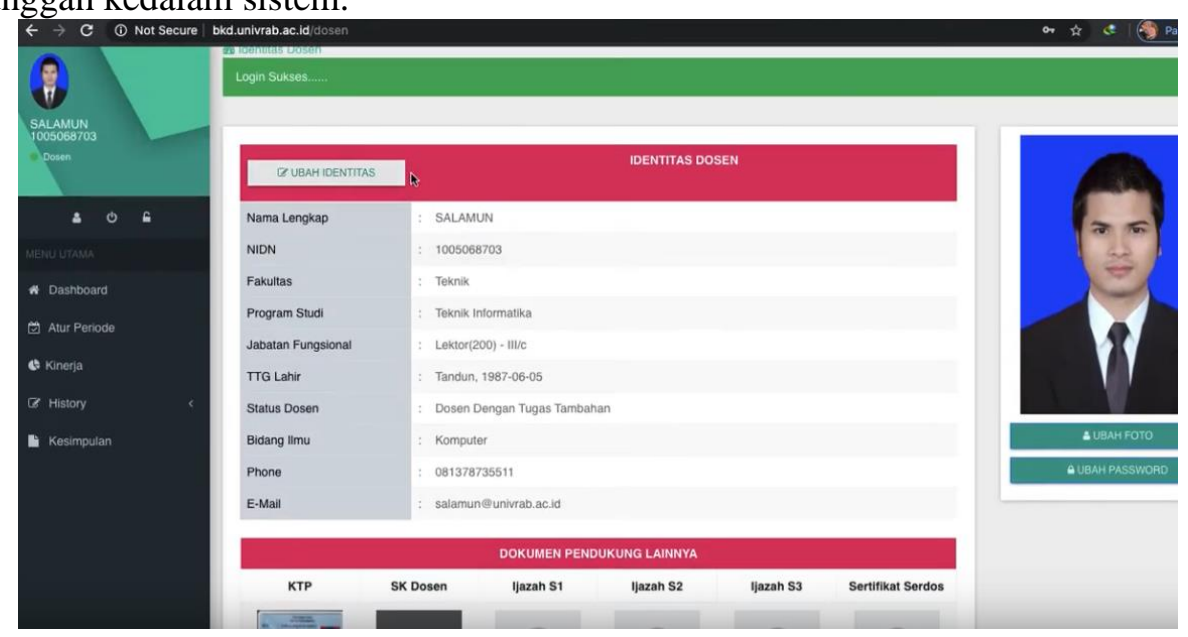

Gambar 5. Dashboard Pengguna

Dosen dapat melakukan aktivitas pengisian data rencana kerja maupun laporan kinerja pada akun masing-masing dosen seperti pada gambar 6 .

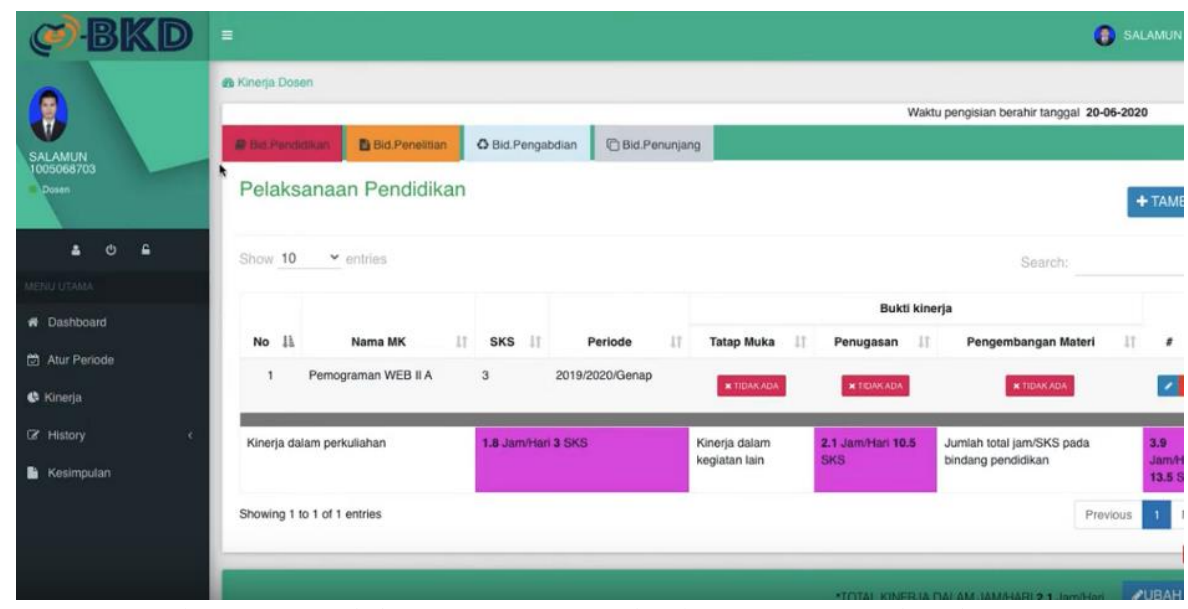

Gambar 6. Pengisian Rencana Kerja dan Laporan Kinerja Dosen 
Selanjutnya pimpinan khususnya dekan fakultas akanmemeriksa setiap item kinerja yang diakui oleh dosen, pimpinan bisa melihat kinerja apa saja yang akui oleh dosen, dalam hal ini dosen mengisi 4 kinerja utama yaitu kinerja bidang pwndidikan, kinerja bidang penelitian, kinerja bidang pengabdian dan kinerja bidang penunjang. Setelah dosen mengisi setiap kinera maka akanm uncul rekapitulasikeseluruhan pada akun pimpinan mereka. Tampilan yang muncul pada hak akses pimpinan lebih kurang seperti gambar 9 dibawah ini, Rencana kerja yang diinputkan oleh Dosen akan ditinjau dan diverifikasi oleh atasan Dosen yang bersangkutan, sedangkan laporan kinerja akan ditinjau dan diverifikasi oleh asesor Dosen seperti terlihat pada gambar 7 berikut.

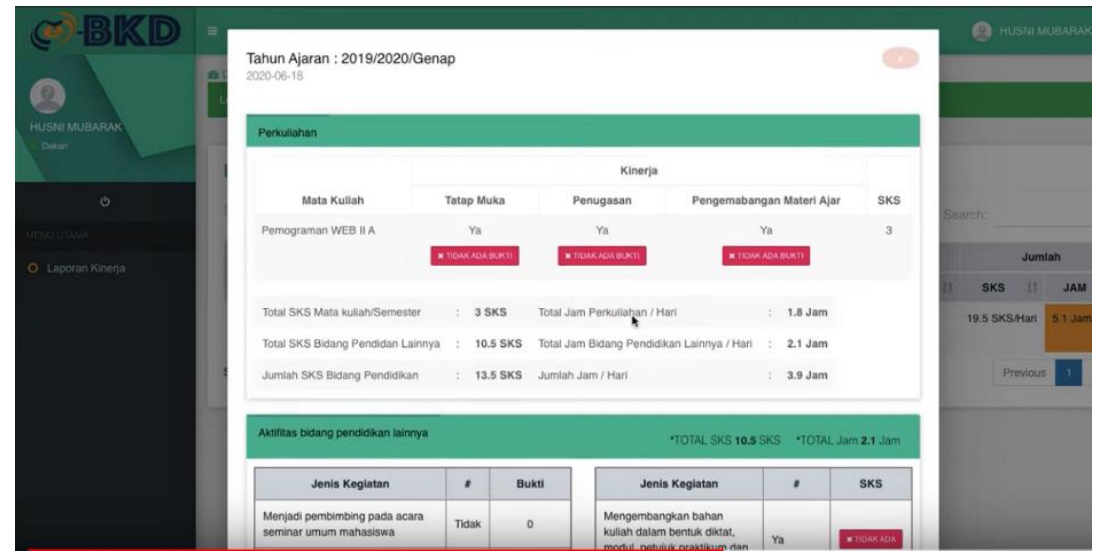

Gambar 7. Peninjauan dan Pemeriksaan Rencana Kerja atau Laporan Kinerja Dosen

Seluruh Rencana Kerja atau Laporan Kinerja Dosen dapat dipantau oleh pihak Perguruan Tinggi melalui bagian kepegawaian, agar dapat memberikan informasi yang diinginkan seperti pada gambar 8. Pada bagian ini, dosen bisa melihat kembali hasil dari inputan kinerja mereka yang di akui, untuk melakukan perubahan data dosen dapat beralih pada menu histori, pada menu ini dosen bisa merubah kinerja mereka jika terdapat kesalahan. Untuk gambar 8 ini adalah tampilan pelaporan kinerja dosen, tampilan ini bisa muncul jika semua kinerja sudah di isi lengkap yaitu kinerja bidang pendidikan, bidang penelitian, bidang pengabdian, dan bidang penunjang pada menu kinerja pada gambar 6 .

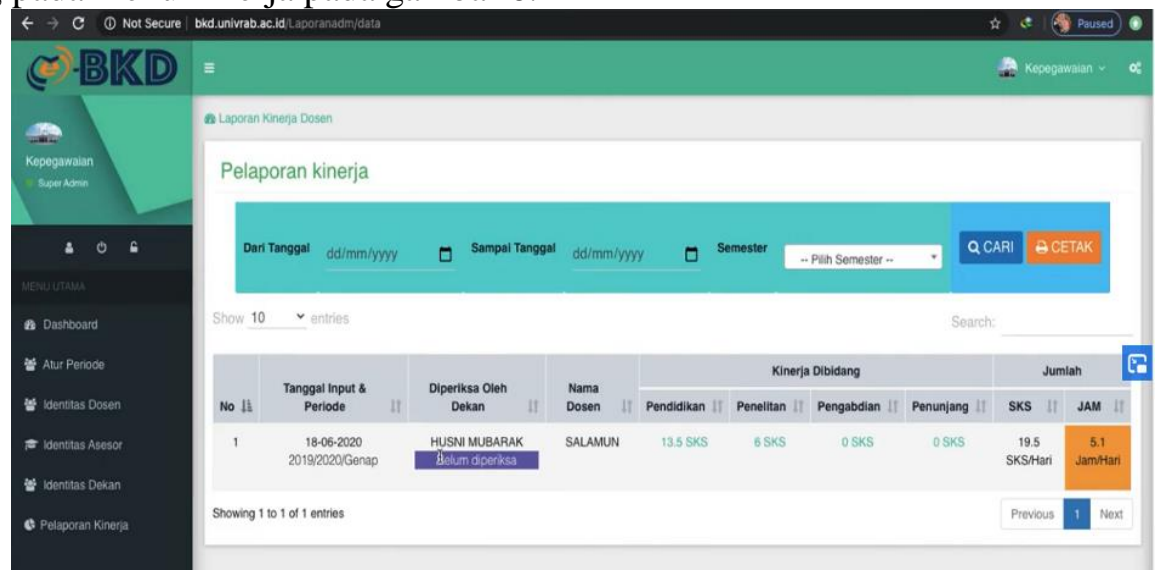

Gambar 8. Pelaporan Keseluruhan Dosen

Sebelum dipergunakan secara luas di lingkungan Universitas Abdurrab, Peneliti melakukan beberapa pengujian supaya untuk memastikan Sistem monitoring kinerja dapat berjalan dan bisa segera diimplementasikan. Adapun pengujian yang dilakukan diantaranya:

3.1 Pengujian Pengguna Sistem

Beberapa pengguna dilibatkan dalam pengujian sistem, tentunya yang telah disebutkan sebagai entitas seperti pada gambar 3. pengujian diawali dengan membagikan panduan pengguanaan terlebih dahulu dan memberikan kesempatan kepada entitas yang terlibat untuk 
mempelajarinya. Pengujian lebih ditekankan pada aspek penguasaan terhadap penggunaan sistem ini. Adapun hasil pengujiannya pada tabel 1 adalah sebagai berikut:

Tabel 1. Pengujian Terhadap Entitas Pengguna Sistem

\begin{tabular}{|c|c|c|c|c|}
\hline \multirow[b]{2}{*}{ No } & \multirow[b]{2}{*}{ Entitas } & \multicolumn{3}{|c|}{ Aspek Penguasaan } \\
\hline & & $\begin{array}{l}\text { Tidak } \\
\text { paham }\end{array}$ & $\begin{array}{l}\text { Sedikit / } \\
\text { sebagian }\end{array}$ & Paham \\
\hline 1 & Dosen & - & - & $\sqrt{ }$ \\
\hline 2 & Atasan Dosen & - & - & $\sqrt{ }$ \\
\hline 3 & Asesor & - & - & $\sqrt{ }$ \\
\hline 4 & kepegawaian & - & - & $\sqrt{ }$ \\
\hline 5 & Rektor & - & - & $\sqrt{ }$ \\
\hline
\end{tabular}

\subsection{Pengujian kelayakan Sistem}

Aplikasi dari sistem monitoring kinerja dosen yang dibangun merupakan aplikasi berbasis $w e b$, tujuannya agar entitas yang terlibat dapat mengaksesnya dari mana saja, kapan saja, dan dapat diakses melalui media yang beragam (seperti laptop, PC, smartphone, dan lain-lain). Adapun hasil yang pengujian didapat berdasarkan parameter-parameter yang telah ditentukan:

Tabel 2 Pengujian Terhadap Kelayakan Sistem

\begin{tabular}{llcccc}
\hline No & \multicolumn{1}{c}{ Parameter } & Aspek & \multicolumn{3}{c}{ Keadaan } \\
\cline { 4 - 5 } & & Kemudahan & $\begin{array}{c}\text { Tidak } \\
\text { memadai }\end{array}$ & $\begin{array}{c}\text { Tidak } \\
\text { begitu }\end{array}$ & Memadai \\
\hline $\mathbf{1}$ & User Interface & fleksibilitas & - & - & $\sqrt{ }$ \\
\hline $\mathbf{2}$ & Ragam penggunaan media & Waktu tunggu akses & - & - & $\sqrt{ }$ \\
\hline $\mathbf{3}$ & Koneksi & Kelayakan & - & - & $\sqrt{ }$ \\
\hline $\mathbf{4}$ & Hosting & Kehandalan & - & - & $\sqrt{ }$ \\
\hline $\mathbf{5}$ & Keamanan & & & - & \\
\hline
\end{tabular}

\subsection{Pengujian Kelayakan Aplikasi}

Pengujian terhadap aplikasi dilakukan per modul untuk mengetahui respon yang dihasilkan dari sistem. Pengujian dilakukan dengan menggunakan metode blackbox, yaitu teknik pengujian aplikasi yang dilakukan per bait kode atau modul untuk mengetahui luaran yang dihasilkan jika kode atau modul dieksekusi. Adapun hasilnya dapat sebagai berikut:

Tabel 3. Pengujian Terhadap Aplikasi

\begin{tabular}{|c|c|c|c|c|}
\hline \multirow[t]{2}{*}{ No } & \multirow[t]{2}{*}{ Modul } & \multirow{2}{*}{$\begin{array}{c}\text { Aspek yang } \\
\text { diuji }\end{array}$} & \multicolumn{2}{|c|}{ Kesesuaian luaran } \\
\hline & & & Sesuai & Tidak sesuai \\
\hline 1 & new_user & $\begin{array}{l}\text { Save, edit, delete, } \\
\text { new, view }\end{array}$ & $\sqrt{ }$ & - \\
\hline 2 & $\begin{array}{l}\text { login (lecturer, lecturer_spv, } \\
\text { assessor, hrd, rector) }\end{array}$ & Login, logout & $\sqrt{ }$ & - \\
\hline 3 & Lecturer_biodata & Save, edit, view & $\sqrt{ }$ & - \\
\hline 4 & Lecturer_activity_program & $\begin{array}{l}\text { Save, edit, delete, } \\
\text { new, view, print }\end{array}$ & $\sqrt{ }$ & - \\
\hline 5 & Lecturer_activity_report & $\begin{array}{l}\text { Save, edit, delete, } \\
\text { new, view, print }\end{array}$ & $\sqrt{ }$ & - \\
\hline 6 & $\begin{array}{l}\text { Verify (lecturer_spv dan } \\
\text { assessor) }\end{array}$ & View, verification & $\sqrt{ }$ & - \\
\hline 7 & summary & $\begin{array}{l}\text { Activity program } \\
\text { all lecturer, } \\
\text { activity report all } \\
\text { lecturer }\end{array}$ & $\sqrt{ }$ & - \\
\hline
\end{tabular}


Dari penelitian yang telah peneliti lakukan, sistem yang dibangun memiliki beberapa kelebihan diantarnya: 1) Sistem ini dibangun berdasarkan algoritma yang merujuk kepada perhitungan rubrik beban kerja Dosen yang dikeluarkan oleh RistekDikti. 2) Sistem dapat memperlihatkan kinerja Dosen dalam hitungan jam per minggu, yang nantinya dapat berguna untuk bagian Kepegawaian maupun Rektorat dalam melihat perkembangan kinerja Dosen. 3) sistem yang dibangun dapat melakukan pemeringkatan kinerja Dosen berdasarkan empat kategori; diantaranya: luar biasa, kinerja bagus, kinerja cukup, dan kinerja kurang. Pemeringkatan ini dilakukan agar Pimpinan dapat mengambil keputusan berdasarkan kinerja yang dilaporkan Dosen bersangkutan. 4) Tentunya, pihak atasan Dosen maupun Asesor dapat melakukan pemantauan, koreksi, dan pemberian saran atas pelaporan kinerja Dosen sebelum dilakukan verifikasi dan pengesahan. Sehingga informasi terkait perbaikan dan peningkatan performa dapat diketahui hanya dengan menggunakan sistem ini.

\section{Kesimpulan}

Beberapa hal yang telah dilakukan dalam penelitian ini yang menjadi poin penting dan dapat dijadikan kesimpulan diantaranya yaitu: sistem monitoring kinerja dosen telah dibangun berbasis web dan dapat mengakomodir tidak hanya dosen yang telah bersertifikasi, namun juga dosen yang belum bersertifikasi. Mekanisme dan bobot penilaian diadopsi dari sistem yang berjalan pada saat ini yang berasal dari panduan atau rubrik BKD yang dikeluarkan oleh Kementerian Ristek dan Dikti. Setelah selesai dirancang, sistem monitoring kinerja dosen telah diimplementasikan dan dilakukan uji coba kelayakan, sehingga aplikasi ini bisa dipakai oleh entitas yang terlibat dalam sistem ini. Selain itu, sistem yang dibangun dapat menginformasikan besaran jam pada setiap aktivitas tridharma yang dilakukan Dosen untuk memudahkan proses penilaian maupun pertimbangan promosi atau demosi dari atasan maupun Universitas. Kontribusi dalam penelitian ini terlihat nyata bagi kalangan dosen dan pimpinan universitas, yaitu kalangan dosen mendapatkan sebuah kemudahan dalam melakukan pelaporan kinerja mereka, sedangkan bagi pimpinan universitas memiliki kemudahan dalam memeriksa kinerja dosen dalam 4 bidang yaitu bidang pendidikan, bidang penelitian, bidang pengabdian serta bidang penunjang.

\section{Daftar Pustaka}

[1] T. M. Johan and R. Ahmalia, "Penilaian Mutu Dosen terhadap Tri Dharma Perguruan Tinggi dengan Menerapkan Logica Fuzzy Logic di STIKES Nan Tongga," J. Akad. Baiturrahim Jambi, vol. 8, no. 2, pp. 26-32, 2019.

[2] D. I. Santoso, P. H. Adiwibowo, and A. H. A. Rasyid, "Analisis beban kinerja dosen periode 2012-2016 terhadap pelaksanaan tri dharma pada prodi DIII teknik mesin," JVTE J. Vocat. Tech. Educ., vol. 01, no. 02, pp. 11-18, 2019.

[3] L. Qulub, "Profesionalisme pendidik dalam proses pembelajaran," Dirasat J. Stud. Islam Perad., vol. 14, no. 01, pp. 29-44, 2019.

[4] Taufik; Ayuningtyas and J. R. Kusumah, "strategi pengembangan mutu perguruan tinggi," J. Ilmu Manaj. Terap., vol. 22, no. 5, pp. 21-32, 2020.

[5] O. M. Anwas, "Kuliah Kerja Nyata Tematik Pos Pemberdayaan Keluarga Sebagai Model Pengabdian Masyarakat Di Perguruan Tinggi," J. Pendidik. dan Kebud., vol. 17, no. 5 , p. $565,2018$.

[6] A. Rifai and O. Arsalan, "Perancangan Sistem Informasi Kinerja Dosen Menggunakan Metode Topsis," in KNTIA, 2017, vol. 4.

[7] A. S. Sinaga, "Implementasi OLAP Menggunakan Dashboard Holistics Software Pada LPPM STMIK Pelita Nusantara," Penelit. Tek. Inform., vol. 2 Nomor 1, no. April, pp. $55-59,2019$.

[8] I. Effendy and A. M. Bakti, "Integrasi Smart Attendance Bagi Dosen Sebagai Upaya Peningkatan Kinerja," Klik-Kumpulan J. Ilmu Komput., vol. 6, no. 3, pp. 317-326, 2019. 
[9] Y. Yuniarto, "Pengaruh Motivasi Dan Insentif Terhadap Penilaian Prestasi Kerja Dosen Tetap Di Universitas Bunda Mulia," Bus. Manag. J., vol. 8, no. 1, pp. 91-107, 2017.

[10] E. Y. Anggraeni, Pengantar Sistem Informasi. Penerbit Andi, 2017.

[11] F. Adzim, "Peranan Sistem Informasi Akuntansi sebagai Alat Bantu Manajemen dalam Pengambilan Keputusan Anggaran Biaya pada Perusahaan Daerah Air Minum (PDAM) Kota Makassar," Perspektif, vol. 02, no. 01, pp. 173-179, 2017.

[12] R. Riska, A. Amroni, and J. Devitra, "perancangan sistem informasi administrasi kependudukan pada kantor desa lambur i kabupaten tanjung jabung timur," J. Ilm. Mhs. Sist. Inf., vol. 1, no. 2, pp. 74-81, 2019.

[13] S. E. NAFIUDIN, Sistem informasi manajemen. Penerbit Qiara Media, 2019.

[14] I. P. Sari and D. Arisandi, "Sistem Informasi Manajemen Klinik Gigi Berbasis Client Server," Rabit J. Teknol. dan Sist. Inf. Univrab, vol. 2, no. 1, pp. 176-185, 2017.

[15] E. Sumantri, "Analisa Dan Pengembangan Sistem Penjualan Dan Pembelian Barang Dengan Metode Waterfall Studi Kasus Koperasi Karyawan Pt. Di," J. Chem. Inf. Model., vol. 53, no. 9, pp. 1689-1699, 2019.

[16] Siti Monalisa and Boni Kurniadi, "Sistem Informasi Monitoring Perkembangan Skripsi dengan Reminder System untuk Mahasiswa," Digit. Zo. J. Teknol. Inf. dan Komun., vol. 10, no. 1, pp. 23-32, 2019.

[17] Andri and Suyanto, "Sistem Informasi Penentuan Guru Terbaik Berbasis Kinerja pada Pondok Pesantren Qodratullah," Digit. Zo. J. Teknol. Inf. dan Komun., vol. 11, no. 1, pp. 108-119, 2020.

[18] M. Kramer, "Best Practices in Systems Development Lifecycle: an Analyses Based on the Waterfall Model," Rev. Bus. Financ. Stud., vol. 9, no. 1, pp. 77-84, 2018.

[19] H. S. Modi, N. K. Singh, and H. P. Chauhan, "Comprehensive Analysis of Software Development Life Cycle Models," Int. Res. J. Eng. Technol., vol. 4, no. 6, pp. 117-122, 2017.

[20] S. M. Salve, S. N. Samreen, and N. K. Valmik, "A Comparative Study of Software Development Life Cycle Models," Int. J. Appl. or Innov. Eng. Manag., vol. 5, no. 02, pp. 696-700, 2018.

[21] B. Unhelkar, Software engineering with uml. CRC Press, 2017.

[22] D. Rajagopal and K. Thilakavalli, "A Study: UML for OOA and OOD.," Int. J. Knowl. Content Dev. Technol., vol. 7, no. 2, pp. 5-20, 2017.

[23] D. S. adillah Maylawati, M. A. Ramdhani, and A. S. Amin, "Tracing the linkage of several Unified Modelling Language diagrams in software modelling based on best practices," Int. J. Eng. Technol., vol. 7, no. 2.29 Special Issue 29, pp. 776-780, 2018.

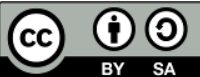

Digital Zone: Jurnal Teknologi Informasi dan Komunikasi is licensed under a_Creative Commons Attribution International (CC BY-SA 4.0) 